\title{
CORROSION OF OPEN-VALLEY FLASHINGS
}

\author{
By K. Hilding Beij
}

\section{ABSTRACT}

In recent years some trouble has been caused by corrosion of copper flashings, particularly of open-valley flashings on buildings with shingle roofs. Sixteenounce copper may be perforated in 15 to 20 years under severe conditions of service. Failures have been found in a few localities only. They seem to be more frequent in New York City and its environs than elsewhere in the Eastern and Central States. One case from Washington, D. C., is significant for here the corrosion occurred where one sheet of copper overlapped another.

The corrosion, for convenience called line corrosion, results in a narrow line of holes or cracks immediately under the edge of the overlying roofing. It appears to be an accelerated attack due to differential aeration of the water retained by capillarity between the roofing and the flashing after a rainfall. This water is shielded from the air except along the edge of the roofing where it is freely exposed.

Accelerated corrosion tests showed that a solution containing both sulphur dioxide and sodium chloride produced rapid line corrosion. Solutions of either alone produced no visible line corrosion in the same length of time. This result suggests that under ordinary conditions line corrosion will be found only in cities near the seacoast. The rate of corrosion depends in large measure on the roofing material. A porous, absorbent roofing, such as wood shingles, holds more water in contact with the flashing after a rainfall and dries out more slowly than a relatively impervious material like slate. Hence, more rapid corrosion takes place.

The laboratory tests indicate that a simple and inexpensive modification in construction will eliminate troubles due to line corrosion. This modification consists of the insertion of a smoothly finished hardwood strip between the roofing and the flashing. The strip should be placed about an inch back of the edge of the roofing and nailed firmly and tightly to the flashing. In the accelerated tests, specimens made in this way were unaffected by more than three times the test exposure which caused line corrosion failure of specimens without the strip. It is reasonable to believe that a similar difference will be found under service conditions. If so, then no appreciable line corrosion would occur with the modified construction in 50 years or more even under conditions as severe as those in New York City and its environs.

\section{CONTENTS}

I. Introduction

II. Flashing failures. 939

III. Experimental work

1. First series of tests... 940

2. Results of first series of tests

3. Second series of tests

4. Results of second series of tests

IV. Discussion of line corrosion ...

V. Summary

\section{INTRODUCTION}

For several years the Bureau of Standards and the Copper and Brass Research Association have been conducting a joint investigation of problems concerning copper roofing, the chief object of the investi- 
gation being to increase the usefulness of copper as a building material. One of these problems was the peculiar form of localized corrosion which sometimes occurs in sheet copper when used for the flashing of open valleys, According to all available information, copper flashings very rarely fail by corrosion and such failures appear to be confined to a few localities. However, copper is a material whose use for roofing purposes is based on its well recognized resistance to destructive atmospheric agencies. Therefore, any factor which tends to limit the life of copper roofing, even to a slight degree, is of far greater import than it would be for a cheaper material not selected primarily for long life.

The purpose of the investigation discussed in this paper was to discover the causes of the corrosion of valley flashings and to find some

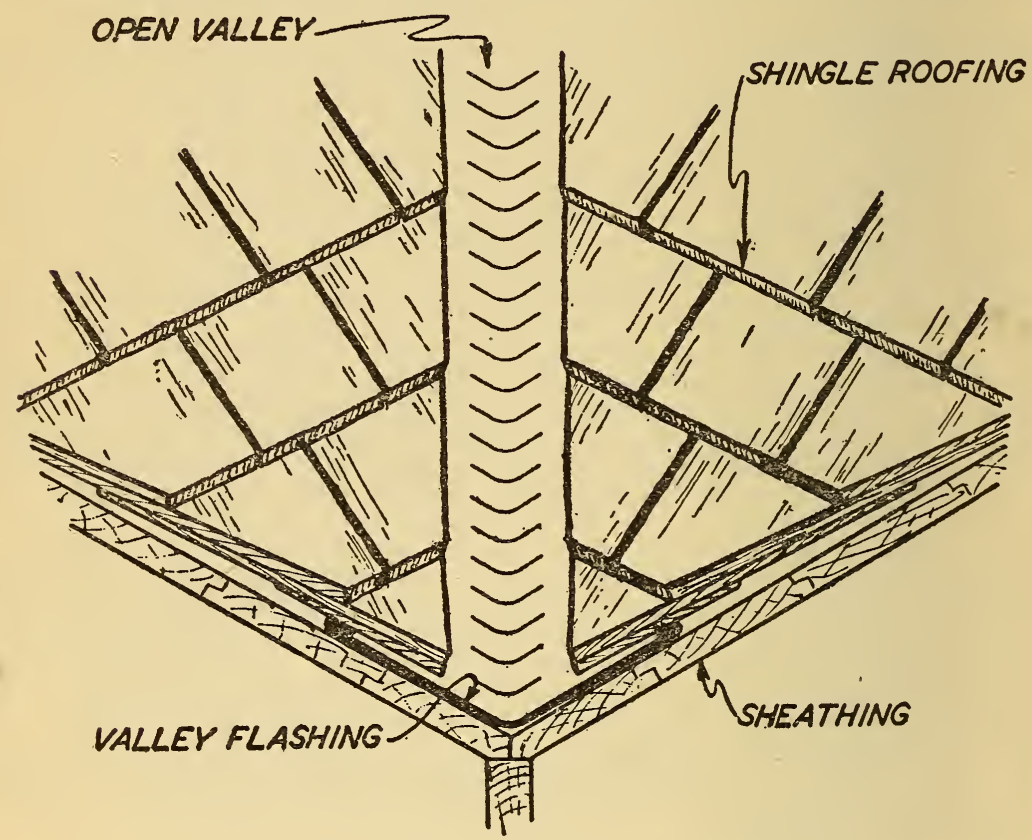

Figure 1.-Diagram of an open valley

means for eliminating them, so that the service life of a roof will not be limited by the life of the flashing. Further, it is important to be able to recognize the circumstances under which such corrosion is likely to be serious enough to warrant precautionary measures. In order to attain these ends it was necessary to develop an accelerated test which would reproduce actual conditions as nearly as possible.

For convenience, some of the terms used in this paper are defined. Roofing denotes the material which covers the major portion of the roof of a building. Flashing is sheet metal applied on various parts of the roof to ensure protection against leakage. When two sloping roof surfaces intersect in a reentrant angle, the trough thus formed is called a valley. If the roofing is continuous through the valley, the valley is closed; whereas if the roofing is not continuous, leaving a channel in the bottom of the valley, the valley is called open. The 
B. S. Journal of Research, RP123

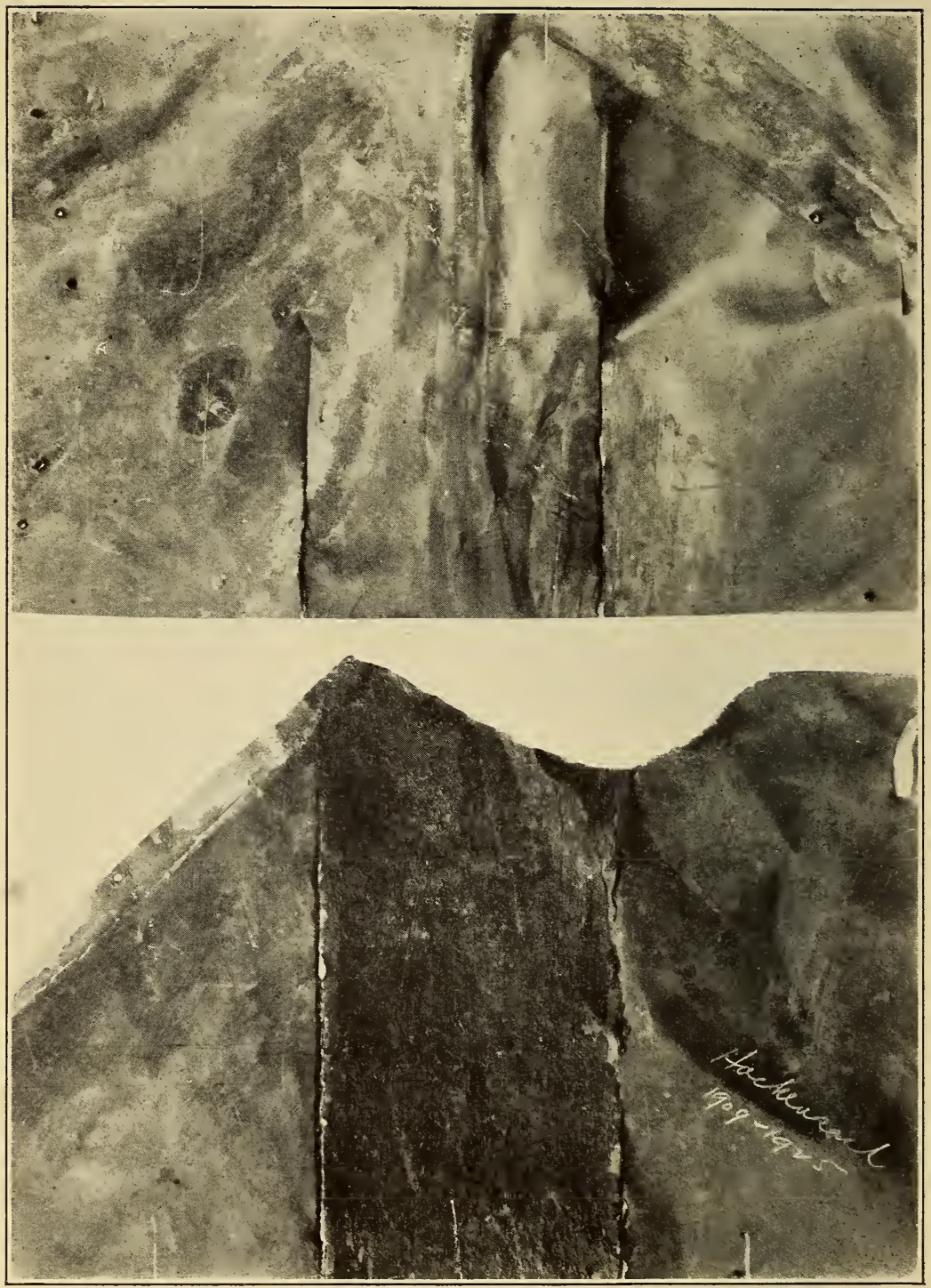

FrgURE 2.-Sections of an open-valley flashing which had failed in service Approximately one-fourth size. 
channel of an open valley is lined with sheet metal which extends up under the roofing on each side and this lining is the valley flashing. Figure 1 shows the essential features of an open valley where the flashing is applied in the usual manner.

The term line corrosion is used to designate localized corrosion occurring in a narrow band from $1 / 32$ to $3 / 32$ inch wide in the flashing located under the very edge of the overlying roofing.

\section{FLASHING FAILURES}

Sections of a valley flashing which had failed in service are illustrated in Figure 2. These specimens were removed from a residence in Hackensack, N. J., about 16 years after the construction of the building. The roofing was "Creo-dipt" shingles and the flashing was 16-ounce Roofing Temper (soft) copper (16 ounces per square foot, 0.0216 inch nominal thickness). This example is typical of other failures except that in most cases repairs are made as soon as the flashing has been penetrated at any point and before the continuous crack has been formed.

The upper specimen in the photograph shows the appearance of the under surface of the flashing. Note the extreme localization of the corrosion, which has penetrated the copper in two very narrow bands $1 / 16$ to $3 / 32$ inch wide, and the very good condition of the copper elsewhere.

The lower specimen in the photograph, taken from another position in the same valley, shows the upper surface of the flashing. The central darker portion, which is about 5 inches wide, formed the open part of the valley. The dark and rough appearance of this part is due to paint applied in an effort to stop the corrosion. The two side portions of the specimen were the parts covered by the overlying shingles. The copper was evidently in perfect condition save for the two cracks located along the edge of the overlying shingle roofing.

In practically all of the cases for which definite information is available the roofing was of wood shingles. This has led to the opinion, held by many sheet-metal workers and others interested, that chemical action due to the wood shingles is directly responsible for the corrosion of valley flashings. However, an example very similar in appearance to the valley-flashing failures was found in Washington, D. C., where no wood shingles were present. The corrosion occurred on a 3-inch stack used to carry off hot gases and fumes from two gas heaters. At each joint of the stack, where one section overlapped another, narrow grooves and cracks were found. These cracks were so strikingly similar in their appearance and their location under the edge of the overlapping section to the failures in the valley flashings, such as that shown in Figure 2, as to lead to the conviction that the same causes were operating. Service conditions were exceptionally severe and it was necessary to replace the stack after about 12 years.

Failures of valley flashings are not a common occurrence. Inquiries throughout a large part of the Eastern and Central States have shown that in most localities they are unknown. Actual examples of failures have been found in a limited area around New York City, and in Philadelphia and Erie, $\mathrm{Pa}$. In the area around New York City, $77886^{\circ}-29-8$ 
including western Long Island and, in particular, the Passaic Valley of New Jersey, valley corrosion appears to be more of a problem than elsewhere.

The information on this subject is so meager that no conclusions can be drawn regarding the relation between failures and their location with respect to railroads or factories, orientation and exposure of roof, and other factors which might possibly be of significance. It should be mentioned, however, that on several of the specimens received for examination, the roofing shingles were almost black with soot and cinders from coal smoke.

\section{EXPERIMENTAL WORK}

\section{FIRST SERIES OF TESTS}

The test specimens were furnished by the Copper and Brass Research Association. These consisted of sample roofs about 30

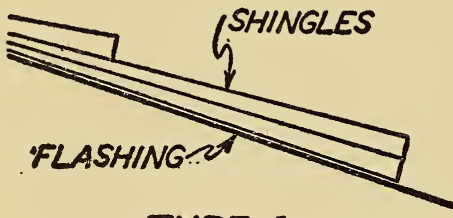

TYPE I

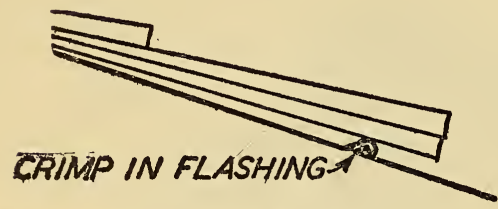

TYPE III

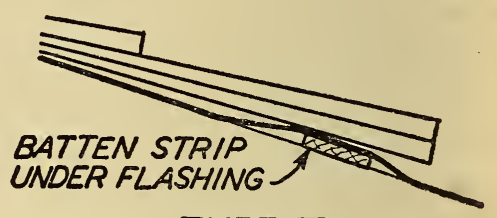

TYPE II

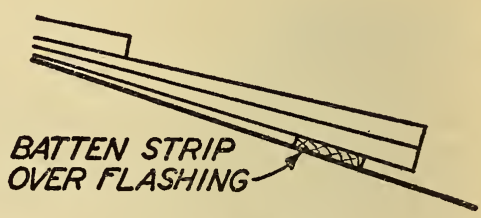

TYPE IV

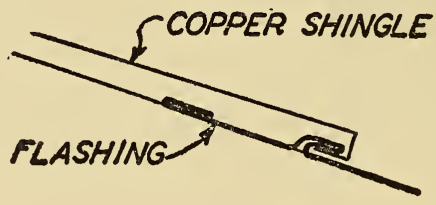

TYPE $\mathbb{Z}$

Figdre 3.-Types of construction for open-valley flashings

inches square mounted on a 1 to 3 pitch, ( 1 inch rise for each 3 inches horizontal). The flashing was placed along the lower edge of each specimen. This flashing was commercial, (electrolytic), sheet copper of 16-ounce gage, which corresponds to a nominal thickness of 0.0216 inch. This gage is the one most commonly used for roofing purposes. Soft copper (Roofing Temper) was used on all specimens except No. 2, which was flashed with hard (Cornice Temper) copper. A descriptive list of the specimens is given in Table 1 and diagrams of the various methods of construction in Figure 3. Figure 4, a photo- 
graph taken while tests were in progress, gives a clear idea of the appearance of the specimens.

The solutions were supplied from a large copper-lined tank shown to the left of Figure 4. From the tank extended two perforated brass pipes, one over each row of specimens just forward of the back edges of the specimens. By this arrangement, solution was distributed evenly over the entire width of the specimens and flowed over practically all of the roofing before striking the flashing. By placing copper wires in the holes of the pipes and adjusting the gradients, very nearly the same flow was obtained over each specimen. The composition of the solutions was approximately as given later, but no attempts were made to obtain great accuracy. The metal of the distributing system was, of course, attacked and this changed the composition of the solution somewhat before it reached the specimens. However, since all of the specimens received very nearly the same treatment, intercomparisons are valid. Apparatus and specimens were thoroughly cleaned weekly, and oftener if it seemed necessary. A series of five tests was made, all on the same set of specimens.

The complete operation of wetting a specimen by running solution over it, together with the subsequent period of drying, will be called one cycle.

Test No. 1.-Tap water was run over the specimens continuously for seven hours each day (except Sundays). The total amount of water in the system was 36 gallons; this was recirculated at a rate of approximately 1 gallon per minute per specimen. After 16 cycles, which took about three weeks, it was evident that no line corrosion was taking place, atleast at a rate warranting continuance of this procedure.

Test No. 2.-The solution was not recirculated in this or in the subsequent tests of the series.

A 0.4 per cent solution of sulphur dioxide was used. The cycle consisted of a 2-hour period during which the solution was dripping on the specimens, followed by a period of 22 hours for drying. The rate at which the solution was supplied was about 0.3 gallon per specimen per minute. After 34 cycles it was clear that this solution was too weak to bring any results within a reasonable time. Furthermore, it seemed that much shorter cycles could be used to advantage, as more drying-out periods would be obtained in the same length of time. Accordingly, the apparatus was modified so that solution could be run for 3 -minute periods at 3 -hour intervals. ${ }^{1}$ Solution was supplied at the rate of about 0.25 gallon per cycle per specimen. This procedure was followed in all of the remaining tests of the series.

Test No. 3. - In this test a 2 per cent solution of sulphur dioxide was used. Five or six 3 -hour cycles were run five nights each week. No traces of line corrosion could be observed after 192 cycles over a period of about two months.

Test No. 4.-A normal solution, 5.65 per cent, of sodium chloride was used. No definite indications of line corrosion could be detected after 93 cycles in about five weeks.

1 An apparatus which would function automatically at night was necessary. A rubber stopper, fitted to the outlet at the bottom of the solution tank, was operated by a rod passing up through the tank to a cam rotated by weights. A pin on the cam shaft, corresponding to the closed position of the stopper, was checked by the plunger of an electromagnet. Current through the electromagnet moved the plunger, thus releasing the check pin. After one-half turn of the cam, a second pin, corresponding to the open posithus releasing the check pin. After one-half turn of the cam, a second pin, corresponding to the open posi-
tion of the stopper, was checked against the plunger. When the current was cut off, the cam made another half turn to the initial position. The operation of the electromagnet was controlled through a relay by a timing device. This consisted of an ordinary alarm clock with wire brushes soldered to the hands. Four contact points for the hour hand, placed equidistant on the clock face, were connected to one side of the relay and a single contact point for the minute hand to the other side. The electomagnet operated every three hours when the hour and minute hands made contact simultaneously. 
Test No. 5.-The solution was a mixture containing 2 per cent sulphur dioxide and 5.65 per cent sodium chloride. Line corrosion began to be evident almost immediately. This test was continued until all of the specimens had failed. The number of cycles in test No. 5 required for each of the specimens to reach the failure point is reported in Table 1.

TABLE 1.-Descriptive list of specimens and summary of results of first series of tests

\begin{tabular}{|c|c|c|c|c|c|}
\hline $\begin{array}{c}\text { Speci- } \\
\text { men } \\
\text { No. }\end{array}$ & $\begin{array}{l}\text { Type of } \\
\text { con- } \\
\text { struc- } \\
\text { tion } 1\end{array}$ & $\begin{array}{l}\text { Flash- } \\
\text { ing } \\
\text { tem- } \\
\text { per }^{2}\end{array}$ & Roofing material & $\begin{array}{l}\text { Cycles } \\
\text { for } \\
\text { failure }\end{array}$ & Remarks \\
\hline & $\begin{array}{l}\text { I.-. } \\
\text { I.-. } \\
\text { Iİ- } \\
\text { III }\end{array}$ & $\begin{array}{l}\text { R. T- } \\
\text { C. T- } \\
\text { R. T-- } \\
\text { R. T.- } \\
\text { R. T-. }\end{array}$ & $\begin{array}{l}\text { Red cedar shingles. } \\
\text { Cypress shingles } \\
\text { Red cedar shingles. }\end{array}$ & $\begin{array}{r}93 \\
50 \\
99 \\
-9-\end{array}$ & $\begin{array}{l}\text { Line corrosion failure. } \\
\text { Do. } \\
\text { Do. } \\
\text { Line corrosion failure; time not observed. } \\
\text { Do. }\end{array}$ \\
\hline & $\begin{array}{l}\text { I... } \\
\text { IV. } \\
I_{-} \\
\text {IV } \\
\text { V.- }\end{array}$ & $\begin{array}{l}\text { R. T.- } \\
\text { R. T:- } \\
\text { R.T.- } \\
\text { R. T.- } \\
\text { R. T.- }\end{array}$ & $\begin{array}{l}\text { "Creo-dipt"shingles (color } \\
\text { green). } \\
\text { Slate- } \\
\text { Asbestos shingles } \\
\text { Terra cotta Spanish tile..- } \\
\text { Copper shingles (9-ounce } \\
\text { C. T.). }\end{array}$ & $\begin{array}{r}93 \\
187 \\
255 \\
193 \\
(93)\end{array}$ & $\begin{array}{l}\text { Line corrosion failure. } \\
\text { Line corrosion failure, at edge of lath. } \\
\text { Line corrosion failure. } \\
\text { Line corrosion failure, at edge of lath. } \\
\text { Copper shingles failed. No line corrosion. }\end{array}$ \\
\hline
\end{tabular}

1 See Figure 3.

2 R. T. signifies Roofing Temper (soft) copper. C. T. signifies Cornice Temper (hard) copper. All specimens on pitch of $1: 3$ (rise of 1 inch to every 3 inches horizontal).

\section{RESULTS OF THE FIRST SERIES OF TESTS}

During the first test, the water became very strongly impregnated with materials leached out of the shingles. The effect of this solution on the copper was hardly noticeable. At the end of the fourth test, no line corrosion could be observed, in spite of the fact that during all of this time the flashings were exposed to solutions which had run over and soaked through the wood shingles. The evidence indicates that chemical action induced by wood shingles is not a factor of importance in the corrosion of valley flashings. Indeed, if this were the case, failures of valley flashings would be far more common and not restricted to certain localities.

On the other hand, the solution used in test No. 5, a mixture containing sulphur dioxide and sodium chloride, produced very rapid line corrosion. This result seems to account for the fact that most of the known failures have been found in New York City and its environs where the air is contaminated by coal smoke and also carries considerable salt on account of its nearness to the ocean. That no failures have been found in inland cities would then be explained by the very much slower rate of corrosion when sulphur dioxide alone is involved.

In order to make intercomparisons among the specimens it is necessary to adopt some criterion for failure and some means for measuring the endurance or life of a specimen under test. Complete penetration of the flashing at any point under the edge of the overlying roofing, where line corrosion would be expected to occur, was assumed to represent failure of the specimen. In the case of specimens of Type III construction (see fig. 3), complete penetration of the upper layer of copper on the crimp was considered failure. In the first series of tests, the failure of specimens Nos. 4 and 5 could not be observed, as the roofing was not removable. The test life of a specimen was taken as the number of cycles with the sulphur dioxide- 


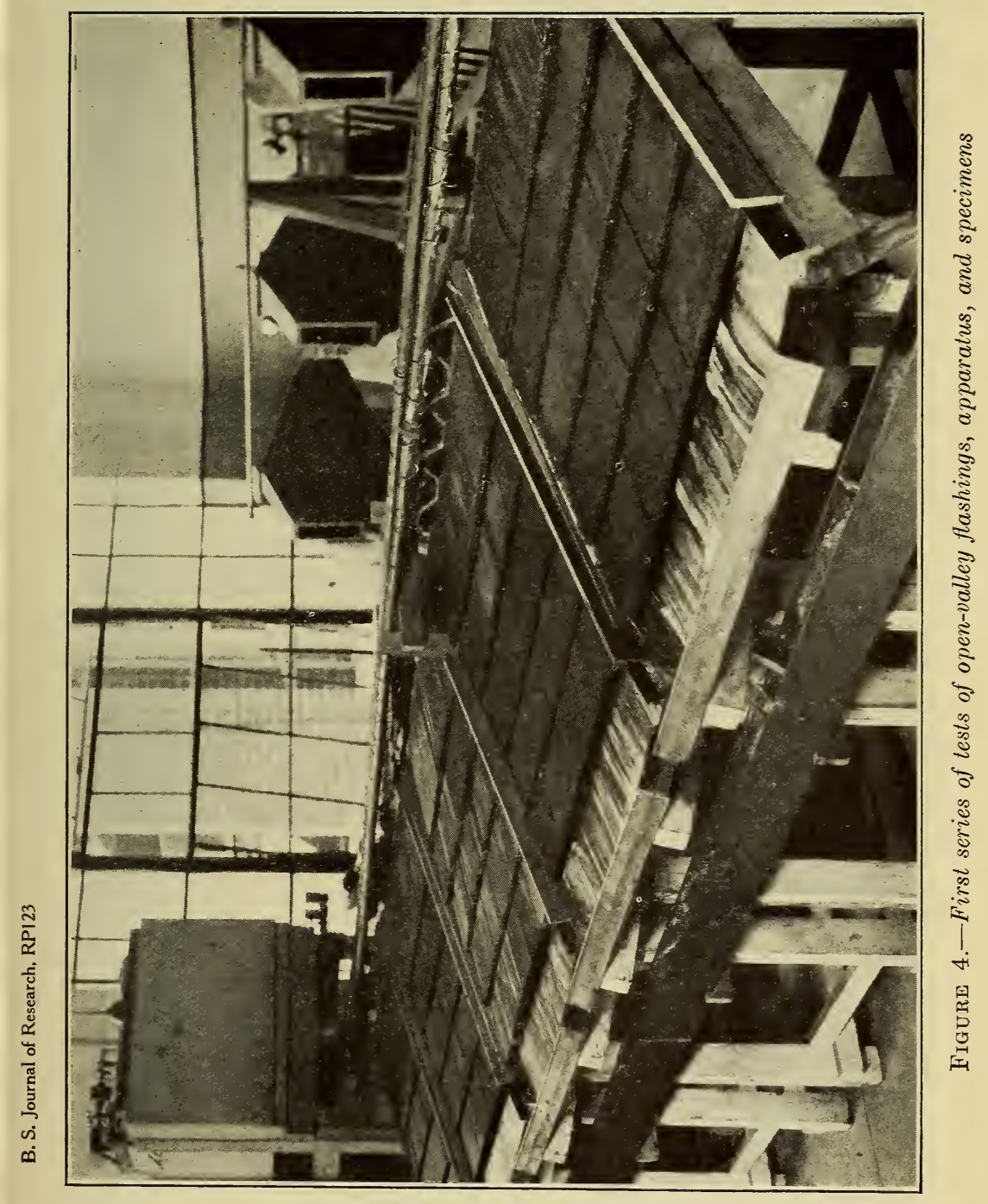




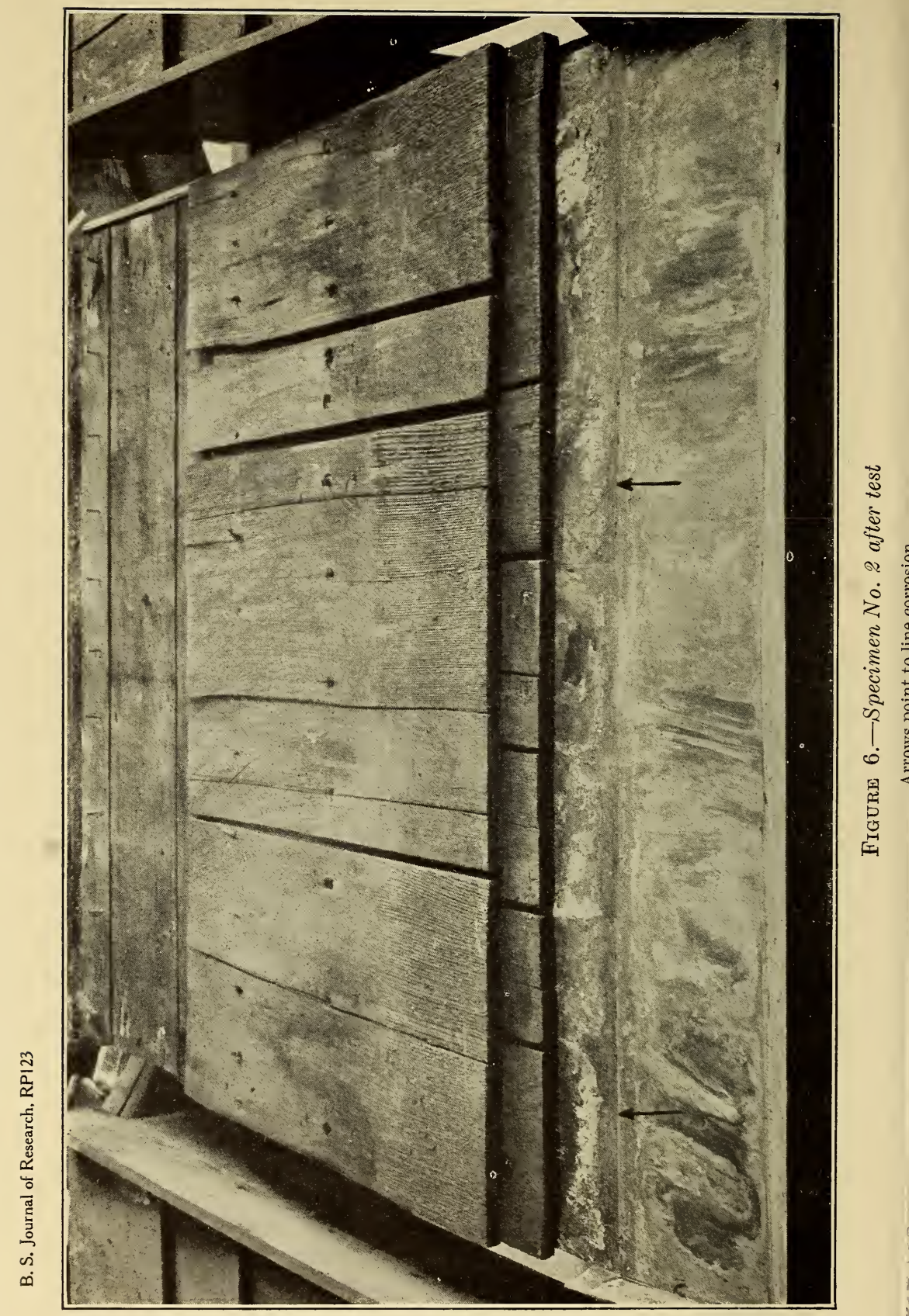


sodium chloride solution required to cause failure. Although other solutions were used in the first series, the line corrosion produced by them could not be detected and was therefore assumed to be negligible. A summary of the results is given in Table 1, and shown graphically in Figure 5. The results for 3 of the 10 specimens are not included in Figure 5 for reasons which will appear later.

The first failure occurred on specimen No. 2, shown in Figure 6. The shingles have been removed and the lower (double) course has

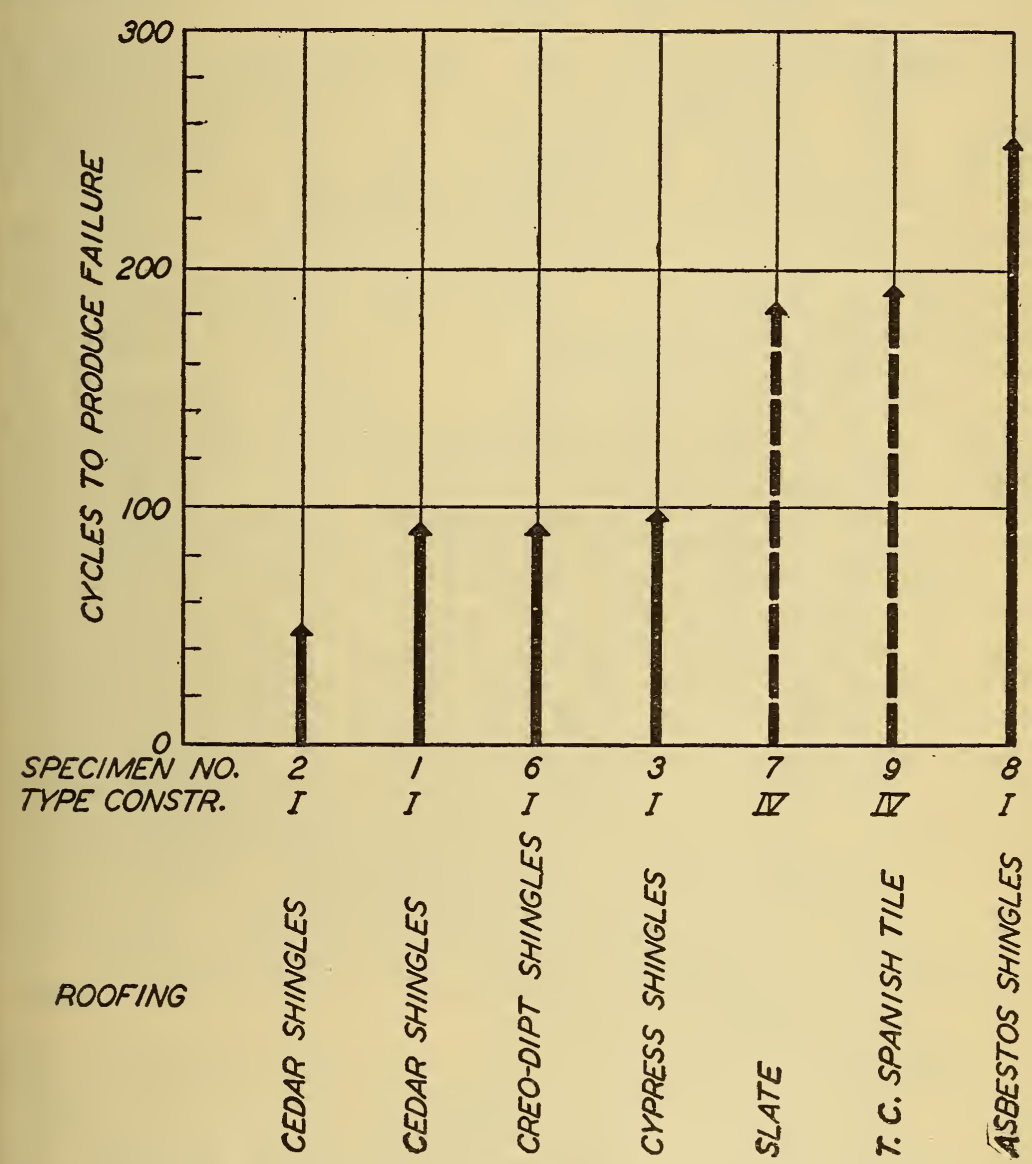

Figdre 5.-Results of first series of tests of open-valley flashings

16-ounce Cornice Temper (hard) copper on specimen No. 2; 16-ounce Roofing Temper (soft) copper on all other specimens. The broken lines indicate that the roofing on these specimens was separated from the flashing by a lath at the edge of which line corrosion occurred.

been separated and replaced a few inches above its original position. The line corrosion shows as a well-defined line (marked by the arrows) running across the specimen. (All along the line was a deep groove which does not show well in the reproduction.) Careful inspection of the photograph will disclose, in addition, a number of holes at various points. At several points the line corrosion extends up along the sides of the shingles for an inch or more. The failure is typical of those which occurred on the other specimens. 
Specimens Nos. 1 and 2 were similar in all respects save that soft copper (Roofing Temper) flashing was used on the first and hard (Cornice Temper) on the second. The hard copper is practically never used for flashing purposes. Specimen No. 2 failed after 50 applications of the mixed solution, while No. 1 required 93 applications for failure. Although results from tests employing only one specimen of a kind can not be considered as entirely conclusive, yet they strongly indicate that no advantage would be gained by substituting hard for soft copper. In fact, line corrosion would probably be more severe with the hard copper.

The test lives of specimens Nos. 1,6 , and 3 were practically the same. These specimens were covered with untreated red-cedar shingles, with "Creo-dipt" shingles, and with untreated cypress shingles, respectively. No difference due to any variations of the chemical composition of the shingles is indicated by the results.

Specimens. Nos. 4 and 5 failed by line corrosion. It is evident, therefore, that the special constructions used on these specimens will not eliminate line corrosion. As the roofing could not be removed during the progress of the tests, it was not possible to determine the test lives of these specimens.

On specimens No. 7 (slate) and No. 9 (Spanish tile), which were intended to be of Type I construction with the roofing touching the flashing, a lath was inserted under the lower course of roofing about 1 inch back of the edge of the roofing. These specimens are accordingly listed as Type IV construction in Table I. Line corrosion appeared at the edge of the lath. The results do not represent true values for the Type I construction of these roofings, and, therefore, they are shown by broken lines in Figure 5. There is one interesting feature with regard to these specimens. Although the laths were wet during each cycle of the test, yet since they were in close contact with the flashing only small amounts of solution were held between laths and flashing. This seemed to account for the prolonged test lives of these two specimens. If this reasoning is correct, it should be possible to still further increase the life of the flashing by using a carefully finished strip of hardwood instead of a rough unfinished lath. The same type of construction (Type IV) applied to wood-shingle roofs is more fully discussed in connection with the second series of tests.

Specimen No. 8, with its roofing of heavy asbestos shingles or tiles, showed a comparatively long test life.

Specimen No. 10 was covered with sheet-copper shingles. These failed by corrosion before any line corrosion of the flashing could be detected. It is of interest to note that these shingles were of hard copper about one-half the thickness of the flashing, and that failure first occurred at bends and corners.

In Figure 5 the specimens, reading from left to right, are arranged in order of increasing test life. It is significant that this is also the order of the specimens when arranged according to the rate of drying from those drying most slowly on the left to those drying most rapidly on the right. Specimens Nos. 1, 2, and 6 dried very slowly, all at about the same rate. No. 3 dried noticeably faster, and Nos. 7,8 , and 9 quite rapidly. A relation between rate of drying and test life is suggested, but no definite conclusions can be based on this small number of specimens. 


\section{SECOND SERIES OF TESTS}

The results of the first series of tests were inconclusive in several respects. In particular, the two special forms of construction (Types

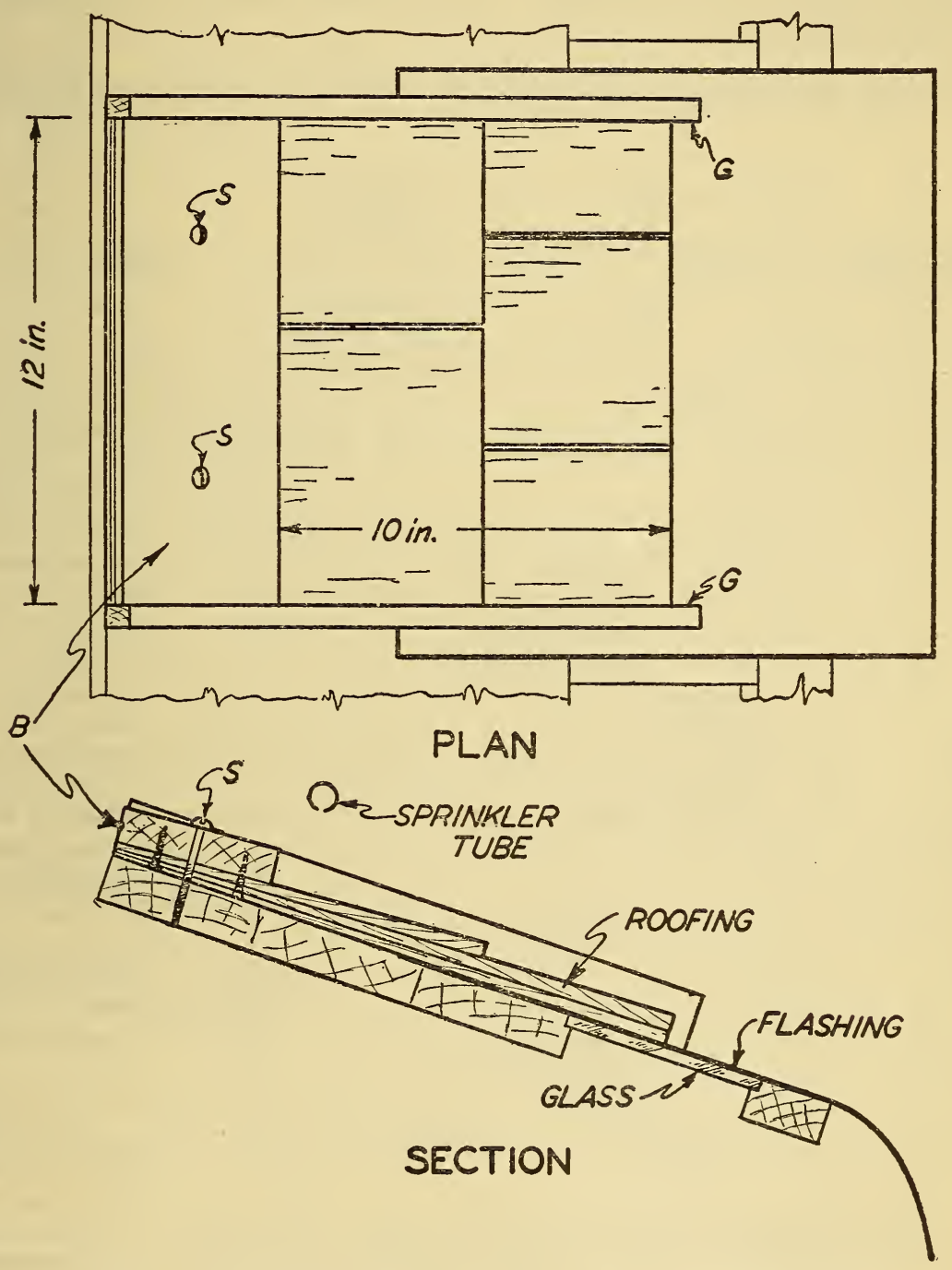

FIGURE 7.-Specimens for second series of tests of open-valley flashings

The roofing is fastened to the block $B$ and the side guards $G$. This 'assembly is held in place by the removable screws $S$.

II and III) did not prove to be immune to line corrosion. Accordingly, a second series was undertaken.

Sketches showing a typical specimen are given in Figure 7. The flashing was nailed to the supporting stand. The glass window in the top of the stand made it possible to detect the first penetration of the flashing. The roofing was attached to a wood block ( $B$ in fig. 7 ) 
and to two guard strips, $G$, which prevented overflow of solution along the sides of the specimen. This assembly was attached to the stand by two screws, $S$. Thus the roofing could be easily removed for inspection of the flashing and could be replaced in its original position and fixed by means of the screws. A descriptive list of the specimens is given in Table 2.

$\mathrm{T}_{\triangle \mathrm{BLE}}$ 2.-Descriptive list of specimens and summary of results of second series of tests

\begin{tabular}{|c|c|c|c|c|c|c|c|}
\hline \multirow{2}{*}{$\begin{array}{l}\text { Speci- } \\
\text { men } \\
\text { No. }\end{array}$} & \multirow{2}{*}{$\begin{array}{l}\text { Type } \\
\text { con } \\
\text { struc- } \\
\text { tion }^{1}\end{array}$} & \multirow{2}{*}{ Pitch } & \multirow{2}{*}{$\begin{array}{l}\text { Roofing } \\
\text { material }\end{array}$} & \multirow{2}{*}{ Remarks } & \multicolumn{2}{|c|}{$\begin{array}{l}\text { Line cor- } \\
\text { rosion, } \\
\text { number of } \\
\text { cycles to- }\end{array}$} & \multirow{2}{*}{ Remarks } \\
\hline & & & & & $\begin{array}{l}\text { First } \\
\text { trace }\end{array}$ & $\begin{array}{l}\text { Fail- } \\
\text { ure }\end{array}$ & \\
\hline 11 . & I & $1: 3$ & Red cedar & & 22 & 138 & Severe line corrosion, one crack. \\
\hline 12 & $\mathrm{I}$ & $1: 2$ & -._do_- & & 22 & 220 & Severe line corrosion, several cracks; \\
\hline 13_ & I & $\begin{array}{l}2: 3 \\
1: 1\end{array}$ & 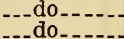 & & $\begin{array}{l}22 \\
71\end{array}$ & $\begin{array}{l}272 \\
148\end{array}$ & Line corrosion, several small holes. \\
\hline 15 & I & $1: 3$ & --do & For continuous drip. & & & $\begin{array}{l}\text { severe corrosion with several } \\
\text { holes. }\end{array}$ \\
\hline 16. & I & $1: 3$ & -do & Heater, for rapid & 22 & 138 & Severe line corrosion, several holes. \\
\hline 17 - & I & $1: 3$ & -.-do_. & Flashing painted un- & 31 & 242 & Severe line corrosion, one small \\
\hline 18. & $I$ & $1: 3$ & $\ldots$ do & $\begin{array}{l}\text { Roofing paper be- } \\
\text { tween fiashing and } \\
\text { shingles. }\end{array}$ & 31 & 220 & Severe line corrosion, one crack. \\
\hline 19. & $\mathbf{I}$ & $1: 3$ & $\begin{array}{l}\text { Composi- } \\
\text { tionshin- }\end{array}$ & & 31 & 158 & Slight line corrosion, one hole. \\
\hline 20 & $\mathbf{I}$ & $1: 3$ & Slate & & 22 & 287 & Line corrosion, several holes. \\
\hline 21 & II & $1: 3$ & $\begin{array}{l}\text { Red cedar } \\
\text { shingles. }\end{array}$ & & 242 & 401 & \\
\hline 22 & II & $1: 3$ & -_do_..... & Flashing painted un- & 242 & 401 & Severe line corrosion, several holes. \\
\hline 23. & II & $1: 1$ & do & 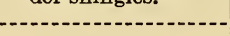 & 401 & & No failure at end of test, 475 cycles. \\
\hline 24 & III & $1: 3$ & $---d o$ & & 138 & 242 & Deeply pitted, hole through first \\
\hline 25 & III & $1: 3$ & ._do_. & Flashing painted un- & 242 & 373 & Do. \\
\hline 26 - & III & $1: 1$ & -..do_. & sinngits & & 242 & Pitted, hole through first layer of \\
\hline 27 - & IV & $1: 3$ & -do_ & & & & No trace of line corrosion at end of \\
\hline 28 & IV & $1: 3$ & -do. & Flashing painted un- & & & Do. \\
\hline 29 & IV & $1: 3$ & do. & Batten strip water- & & & Do. \\
\hline 30. & IV & $1: 1$ & & $\mathbf{p}$ & & & Do. \\
\hline
\end{tabular}

1 See Figure 3.

Glass receptacles and tubing were used in the system for distributing the corrosive solution to the specimens. Joints were of rubber tubing. By adjustment of the sprinkler tubes a fairly uniform flow was obtained over each specimen. This flow was checked occasionally by measuring the run-off from the specimens. About one-tenth of a gallon of solution was required to thoroughly wet a specimen, and the flow was adjusted to give approximately this amount in six minutes. $^{2}$

${ }_{2}$ The arrangement for starting and stopping the flow automatically was the same as that used in the first series of tests, except that a hard-rubber valve, with its stem on the cam shaft, was substituted for the stopper and cam combination. 
The corrosive solution was the same as that used in the final test of the first series, namely, a mixture containing about 5.85 per cent of sodium chloride and 2 per cent of sulphur dioxide. As before, this mixture gave rapid results. It was intended to run six 3 -hour cycles each night. However, this did not always allow the specimens to dry out thoroughly, especially during rainy weather when the humidity was high. Therefore, the schedule was varied at times to suit circumstances. Specimens and apparatus were cleaned at intervals as seemed necessary.

\section{RESULTS OF THE SECOND SERIES OF TESTS}

A résumé of the results is given in Table 2 and the comparative test lives of the specimens are shown graphically in Figure 8. Note in particular, that specimens Nos. 27 to 30 , inclusive, showed no signs of line corrosion at the completion of the test. Although specimen No. 13 had not failed at the end of the test, pitting had progressed almost through the flashing at one point so that failure was imminent.

The action of different roofing materials is well shown by comparing specimens No. 11 (wood shingles), No. 19 (composition shingles), and No. 20 (slate), all of Type I construction. All of these failed by line corrosion, and, as nearly as could be judged by inspection, the total amount of corrosion was about the same in each case. However, the slate specimen (No. 20) which had the least porous or absorbent roofing and, therefore, dried out most rapidly in each cycle, had the longest test life. The composition shingles (No. 19) dried out more slowly than the slate, thus holding a film of water between roofing and flashings for a longer period each time. The failure was correspondingly hastened and the test life considerably shortened. The shingles (No. 11) were quite porous and absorbent, dried out very slowly, and retained liquid in contact with the flashing for a longer time than the other materials. Hence, as anticipated, the test life here is the shortest of all. The effect of the roofing material as regards line corrosion appears to be almost entirely dependent on the length of time which the material can hold solution in contact with the flashing. The more porous and absorbent the material, the shorter will be the test life of the specimen. Accordingly, specimen No. 18, which had a sheet of roofing paper inserted between the shingles and the flashing, should have a test life somewhere between those of the composition shingles and the slate. The roofing paper fitted more closely to the flashing than the composition shingles and, therefore, held back less liquid, so that drying was somewhat more rapid. As can be seen in Figure 8, the test life of specimen No. 18 falls about midway between those of the composition shingles (No. 19) and the slate (No. 20).

It is concluded, on the basis of the results of both series of tests, that wood shingles are not the primary cause of line corrosion, and that practically the only influence of the roofing material on line corrosion depends on its ability to retain water in contact with the flashing. This conclusion is borne out by the data relating to failures of valley flashings. These data show that line corrosion may occur in the absence of any material other than the copper itself. Moreover, failures appear to be restricted to certain localities. They do not occur generally in all places where wood shingles are used. 
If this conclusion is correct, then a specimen mounted on a steep pitch should have a longer test life than a similar specimen with only a slight pitch. For, as the pitch or slope of the roof is increased, water will drain off more completely and less will be retained between

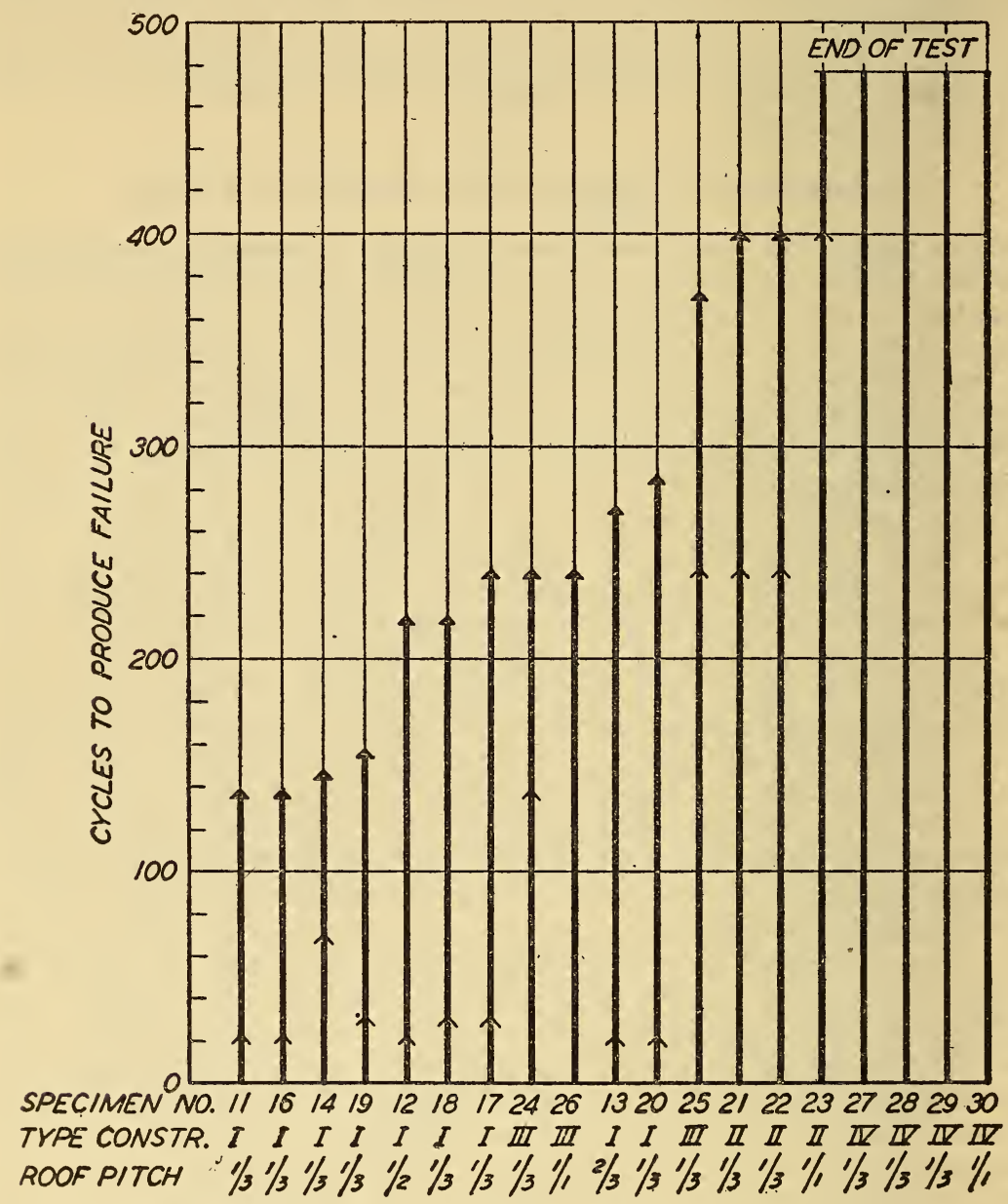

ROOFING ON SPEC.NO. 19 - COMPOSITION SHINGLES

ON SPEC. NO.20 - SLATE

ON ALL OTHERS - RED CEDAR SHINGLES

FIGURE 8.-Results of second series of tests of open-valley flashings

First (light) arrowhead represents first noticed trace of line corrosion. Second (heavy) arrowhead represents failure. All flashings of 16-ounce Roofing Temper (soft) copper.

the roofing and the flashing. Comparing specimens Nos. 11 to 14, inclusive, all of wood shingles but with progressively increasing pitch, it is found that the test life increases as the pitch increases. No. 14 is an apparent contradiction. However, although failure occurred very early on this specimen, severe line corrosion was limited to a small area and most of the specimen was in fairly good condition. It is believed that if some better way of measuring the total amount 
of line corrosion were feasible, this specimen would not be so far out of place with respect to the others. Reduced corrosion on specimens of steeper pitch was also found for other forms of construction-as may be seen by comparing the results for specimens Nos. 21 and 23, and also for specimens Nos. 24 and 26 . It is true that specimen No. 26 failed at about the same time as specimen No. 24 , but the total amount of corrosion over the whole specimen was considerably less.

The attempt was made to determine directly the effect of drying. Specimen No. 16 was provided with an electric heater which accelerated drying. However, the specimen failed at the same time as No. 11, which was allowed to dry without artificial aid. The question arises as to whether the retarding effect of the more rapid drying may not have been overcome by an accelerating effect due to the much higher temperature. Specimen No. 15, which was kept continuously wet except for one day each week, did not fail by definite line corrosion. Careful examination of this specimen while the test was in progress showed that the liquid between the flashing and the roofing was in continual motion. This motion was due to the slow steady flow of solution required to keep the specimen wet. On the specimens periodically wetted and then allowed to dry slowly the solution between roofing and flashing was in a quiet and undisturbed state during the period of drying. The test conditions were not the same in both cases, so that no comparisons of the results are made.

Three possible methods of counteracting line corrosion were studied. These were painting of the flashing, separation of flashing and roofing by building paper, and variations in construction.

The flashing on one specimen of each type of construction was painted with a heavy coat of red lead paint. The painting covered all of the flashing under the roofing and extended about one-half inch beyond the edges of the roofing. No comparison can be made for Type IV construction, since neither painted nor unpainted specimens showed any trace of line corrosion at the conclusion of the test. The unpainted (No. 21) and the painted (No. 22) specimens of Type II construction failed at the same time. On Types I and III the painted specimens showed somewhat increased test life. (Compare No. 17 with No. 11 and No. 25 with No. 24.) The painting apparently has some retarding effect, but not enough to warrant its use as a protective agent.

A sheet of building paper between shingles and flashing increases the test life, as previously mentioned, but not enough to make this expedient of any great value.

A number of intercomparisons are possible for the four types of construction tested. (See fig. 3.) Taking first the specimens Nos. 11, 21,24 , and 27 , all with wood-shingle roofing on 1 to 3 slope, it is found that in order of increasing test life the types of construction are I, III, II, IV. Taking next the specimens with painted flashings (Nos. 17, 22, 25, and 28) we get the same order. Finally for the set of specimens on a steep slope (1 to 1 pitch, specimens Nos. 14, 23, 26 , and 30 ) we find the types of construction again ranked in the same order.

The usual form of construction (Type I) thus appears to be the most susceptible to line corrosion. Type III construction, with a crimp in the copper which supports and raises the lower course of roofing, is a considerable improvement, though much inferior to the remaining two types. 
While it does not offer complete protection, the Type II construction has certain advantages which may make its use desirable with with nonabsorbent roofings like slate or under conditions of service not highly conducive to line corrosion. In the first place, the flashing may be secured by cleats as is the usual practice. Secondly, the batten strips may be placed by the carpenter before the sheet-metal man starts his work. Finally, there is no obstruction to the flow of any water which might seep through the shingles just above the batten strip. Also it might be added that any strips of wood of the right dimensions, such as laths, may be used as batten strips without special preparation. Since sharp bends are undesirable, the proper laying of the flashing is important.

None of the specimens (Nos. 27 to 30 , inclusive) of Type IV construction showed any signs of line corrosion at the end of the test. This type of construction then should prevent line corrosion, or at least retard it to such an extent as not to limit the useful life of the roof. The value of this form of construction is dependent on three considerations. First, only a very small fraction of the water falling on the roof can ever reach the junction between the batten strip and the flashing. Second, the batten strip is in close contact with the flashing and therefore little, if any, water can penetrate between the strip and the flashing. And third, if the strip is of hard, dense wood or is thoroughly waterproofed and has smooth surfaces, it will not hold water by capillarity to any appreciable extent. The strip then tends to prevent the formation of a slowly drying film of water such as causes line corrosion.

In the absence of data to the contrary, it is reasonable to believe that the life of a flashing under actual service conditions on a roof will be directly proportional to its test life. The line corrosion produced by 138 test cycles on specimen No. 1, Type I construction, was about the same in amount as that which is produced in 15 years or more on a roof under the most severe conditions. Therefore if Type IV construction, which was unaffected by 475 test cycles, were used on a roof, the flashing would probably show no signs of line corrosion for 50 years or more.

\section{DISCUSSION OF LINE CORROSION}

The localized intense corrosion, which we have called line corrosion, is an interesting case of the type of attack occurring with differential aeration. Figure 9 is a diagram showing, on a large scale, approximately the relation between roofing, flashing, and retained liquid and the location of the line corrosion. It will be observed that the line corrosion is very close to the edge of the roofing, but definitely back of it. This has been checked on all the test specimens and on four available service specimens. We have then a layer of liquid containing corrosive agents in contact with the flashing, part of the layer being exposed freely to the air and part being shielded by the overlying roofing. The corrosion of the flashing takes place near the region of separation between aerated and nonaerated portions of the solution, but under the nonaerated portion.

Evans ${ }^{3}$ has shown that, in general, when a metal is exposed to a solution, part of which is aerated and part nonaerated, the metal

${ }^{8}$ U. R. Evans, Corrosion of Metals, Arnold \& Co. (2d ed.); 1926. Also, Corrosion of Copper and Copper Alloys, J. Soc. Chem. Ind., 43, p. 127T; 1924. 
under the nonaerated portion will be anodic to that under the aerated portion and will be corroded. If the aeration is accompanied by agitation, such as stirring, copper is an exception to the general rule and the part of the metal under the aerated portion corrodes. However, if differential aeration can be secured without stirring, then copper will behave as other metals and the corrosion will take place on the nonaerated part.

After a rainfall water containing dissolved impurities is retained on a valley flashing for some time in a quiescent state, approximately as shown in Figure 9. Near the solution-air interface there will be a very narrow cathodic area on the flashing under the aerated portion of the solution. Adjacent to this (under the roofing) will be a relatively wide anodic area under the nonaerated portion of the solution. The current density over the anodic area will be a maximum along a narrow band close to the cathodic area, decreasing very rapidly to extremely low values farther away from the cathodic area. Hence, practically all of the corrosion will be concentrated in a narrow band under the very edge of the roofing.

Further studies would be required to work out the reactions which take place with the various solutions. In the tests no account was taken of carbon dioxide or other possible factors which may have been present and

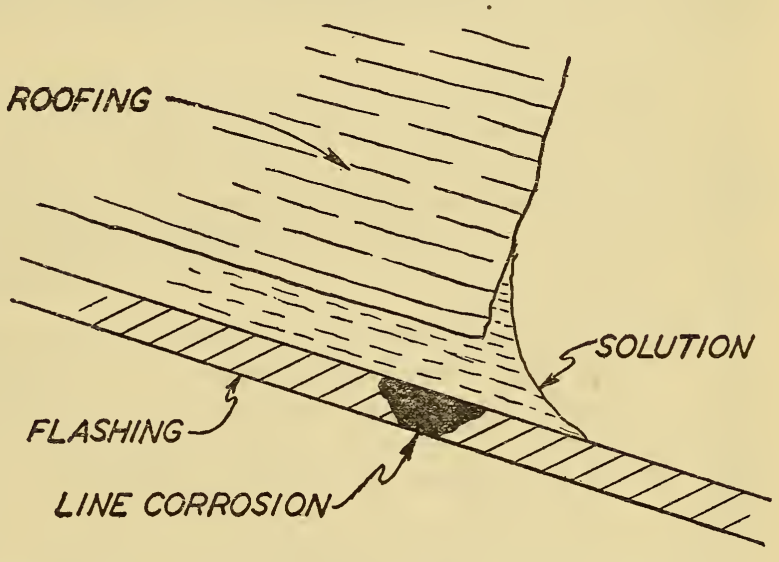

Figure 9.-Diagram of open-valley flashing to illustrate manner in which line corrosion occurs certainly would be

involved under service conditions. With the sulphur dioxide-sodium chloride solution, which produced rapid line corrosion, cuprous chloride and copper sulphate would be formed. There would probably be a tendency for the reaction products to move downward, under the action of gravity, toward the solution-air interface. The cuprous chloride, being insoluble, would be deposited over the flashing and oxidized, in part at least, to basic cuprous chloride by oxygen diffusing through to the deposit. This deposit would form an effective barrier to the further passage of oxygen, thus reinforcing the action of the roofing in preventing access of the air to the underlying copper. Any movement of copper sulphate downward would result in a greater concentration near the edge of the roofing. This may be a factor in the localization of the corrosion.

If line corrosion is to take place on copper-valley flashings, three conditions must be fulfilled. First, the rain water falling on the roof must be contaminated by the atmosphere and by dust and dirt from the roof. The results of the first series of tests, and the fact that the known failures of flashings have occurred in cities not far from 
the seacoast, suggest that line corrosion will not be serious except in the presence of both sulphur dioxide and sodium chloride. Second, rain water must be retained in contact with the flashing for an appreciable time after rainfall has ceased in such a manner that part of it is exposed freely to the air and part of it is shielded. And third, if the line corrosion is to occur in copper, the retained water must not be stirred or agitated. (Compare the results on specimen No. 15 of the second series of tests.) The remedy for line corrosion will consist of preventing the accumulation of any solution in such a manner that differential aeration may occur. The Type IV construction fulfills the necessary conditions in so far as is possible with a reasonably simple and inexpensive construction.

\section{SUMMARY}

The following conclusions are based on the results of the tests supplemented by data obtained from studies of flashing failures:

1. Line corrosion of valley flashings can be reproduced by accelerated corrosion tests.

2. Wood shingles are not the primary cause of line corrosion.

3. Line corrosion may occur not only with wood shingles but also with slate, asbestos shingles, composition shingles, and, under exceptional circumstances, even when one sheet of copper overlaps another.

4. A solution containing a mixture of sulphur dioxide and sodium chloride produces line corrosion far more rapidly than solutions of either substance alone.

5 . The rate at which line corrosion proceeds depends on the solution and on the time during which the solution remains without motion in contact with the flashing.

6 . The length of time for which the solution remains in contact with the flashing after a rainfall depends on the porosity of the roofing. Hence, the more porous and absorbent the roofing material, the more rapid will be the corrosion.

7. On all open-valley flashings, particularly in cities near the seacoast where line corrosion may be expected, a batten strip should be inserted between the flashing and the roofing. This batten strip should be a smoothly finished hardwood strip, preferably waterproofed, having the approximate dimensions of a lath. It should be placed about 1 inch back of the edge of the roofing and nailed firmly and tightly to the flashing. There is reason to believe that, if this precaution is followed, no perceptible line corrosion will occur in 50 years or more of service on a roof under the severe conditions such as are found in New York City and its environs.

Washington, July 10, 1929. 